\title{
Licensing of the NPI Sumr and its implications for sentential negation in Cairene Egyptian Arabic
}

\author{
2011 LSA Annual Meeting Extended Abstract \\ Usama Soltan (usoltan@middlebury.edu) \\ Middlebury College
}

Like several other Arabic dialects, Cairene Egyptian Arabic (CEA) exhibits a two-pattern negation system in the verbal domain: (i) the circumfixal maa...š-pattern, which is used with perfective verb forms, where the predicate appears sandwiched between both negative elements, forming one morphological unit, as in (1a); and (ii) the independent miš-pattern, which is used with imperfective verb forms, where the predicate follows the negation marker, without them forming a unit, as with the future verb form in (1b).
1a. maa-saafir-t-i-šs
b. miš ha-saafir
NEG-travel.PERF-1SG-EV-NEG
NEG FUT-travel.IPFV.1SG
'I did not travel.'
'I will not travel.'

In both patterns, the occurrence of the $-\check{s}$ segment of the negation morpheme is obligatory, as the ungrammaticality of both examples (2) shows.
2a. *maa-saafir-t
b. *maa ha-saafir
NEG-travel.PERF-1SG
NEG FUT-travel.IPFV.1SG
'I did not travel.'
'I will not travel.'

Interestingly, when the Negative Polarity Item (NPI) Sumr (=“ever;” literally=“life/age”) occurs in pre-negative position in the sentence, negation is expressed by maa (3a,c), and the -š segment is not allowed to surface (3b,d). (For convenience, I will translate fumr+negation as never throughout.)
3a. Sumr-ii maa-saafir-t Masr ever-my NEG-travel.PERF-1sG Egypt 'I have never traveled to Egypt.'
b. * Yumr-ii maa-saafir-t-i-š Masr
ever-my NEG-travel.PERF-1SG-EV-NEG Egypt
c. Sumr-ii maa ha-saafir Masr
ever-my NEG FUT-travel.IPFV.1SG Egypt 'I will never travel to Egypt.'
d. *Sumr-ii miš ha-saafir Masr ever-my NEG FUT-travel.IPFV.1SG Egypt

As a marked option in the language, the NPI fumr may also occur in postverbal position, in which case the -š segment is obligatorily realized.
4a. maa-saafir-t-i-*( $\breve{\mathrm{s}})$
Masr Sumr-ii
NEG-travel.PERF-1SG-EV-*(NEG) Egypt ever-my
'I have never traveled to Egypt.'
b. miš/*maa ha-saafir $\quad$ Masr Sumr-ii
NEG/NEG FUT-travel.IPFV.1SG Egypt ever-my

'I will never travel to Egypt.'

In addition, the NPI Sumr may host negation, in which case the suffix -š is also required.

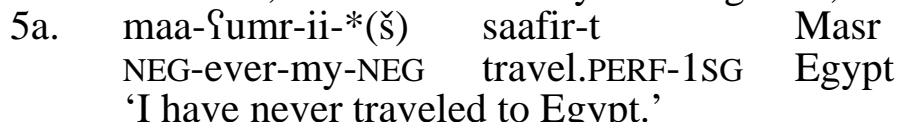

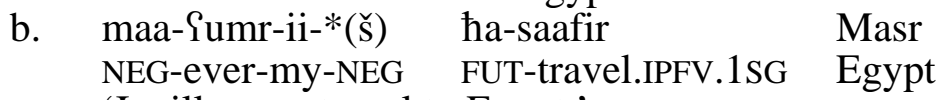

'I will never travel to Egypt.'

Two main questions arise here: First, how can we provide a principled account for the puzzle of -š disappearance with Sumr? Second, what are the implications of this morphosyntactic fact for the analysis of sentential negation in CEA in general? I discuss both questions in this article.

Clearly, any solution to the puzzle of -š disappearance will be tied to how $-\check{s}$ is treated in the grammar. There have been two main approaches regarding the syntactic status of $-\check{s}$ in Arabic dialects: -š as a Spec of NegP (along the lines suggested for French negation in Pollock 1989, Ouhalla 1990, and Moritz and Valois 1994), and -š as part of a discontinuous Neg morpheme (as in Benmamoun 1997, 2000, Bahloul 1996). The structure of NegP under both approaches is as in (6a,b), respectively. 
6a.

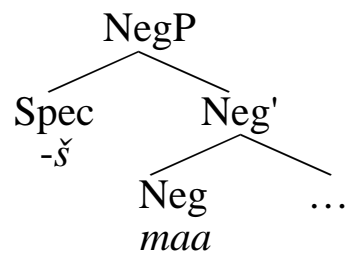

b.

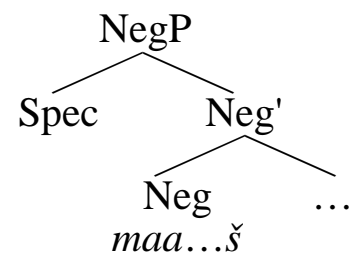

The complementary distribution between -š and \&umr noted above may seem to favor an analysis of sentential negation in CEA as in (6a), under the assumption that both elements are competing for the same position, that is, SpecNegP. Such an analysis, however, fails to explain why no such effect takes place with other NPIs in the language such as lissah (=yet), which requires the realization of $-\check{s}$, regardless of whether it occurs in pre-negative (7a) or postverbal position (7b).

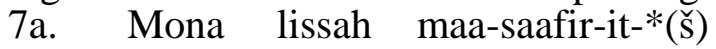

Mona yet NEG-travel.PERF-3SGF-NEG

'Mona has not traveled yet.'

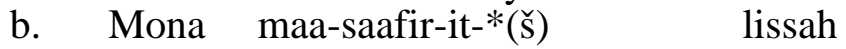

Mona NEG-travel.PERF-3SGF-NEG yet

'Mona has not traveled yet.'

The same holds of other NPIs in the language such as Payy (=any) and the adverbial xaaliS (=at all), both of which may only occur in postverbal position.

$\begin{array}{lll}\text { 8a. Panaa maa-šuf-t-i-*(ك) } & \text { Payy haagah } \\ \text { I } & \text { NEG-see.PERF-1SG-EV-NEG } & \text { any thing }\end{array}$

'I didn't see anything.'

b. Panaa maa-šuf-t-i-*(̌̌ $)$ haagah xaaliS

I NEG-See.PERF-1SG-EV-NEG thing at all

'I didn't see anything at all.'

I conclude then that the structure in (6a) cannot help us resolve the puzzle under consideration.

The same is also true of the discontinuous Neg head analysis in (6b). In particular, it is not clear how to tie the presence of NPIs to -š disappearance under this analysis, let alone why this would happen with some NPIs, but not others. The discontinuous Neg head analysis also forces us to assume a rule at the sub-morphemic level. Neither Benmamoun (2000) nor Bahloul (1996) provides a possible rule, but even if we were able to formulate such a rule, it is not clear why it is always the -š segment, and not the preverbal maa, that disappears in such contexts. In other words, why are sentences like (9) below not attested in CEA?

9. * (umr-ii saafir-t-i-š Masr

ever-my travel.PERF-1SG-EV-NEG Egypt

Intended reading: 'I have never traveled to Egypt.'

I, therefore, conclude that neither analysis of negation in (6) can account for the puzzle of -š disappearance in CEA.

Instead, I would like to argue that a solution is possible if we consider the "formal negativity" of the elements involved. On the basis of synchronic and diachronic evidence, it can be shown that while both -š and lissah are formally marked as negative, fumr is nonnegative. First, -š and lissah cannot appear in nonnegative contexts such as questions without overt negation (5a,b), but fumr can (5c).
10a. *(maa)-šuft-š
Ahmad Pil-nahaar-dah?
NEG-See.PERF.2sgm-NEG Ahmad the-day-this

'Did you see Ahmad today?'

$\begin{array}{lll}\text { b. Ahmad gih } & * \text { (wallaa) lissah? } \\ & \text { Ahmad come.PERF.3sGM or.not } & \text { yet }\end{array}$

'Has Ahmad come or not yet?'

c. Pinta Sumr-ak saafir-it Masr?

you ever-you travel.PERF.2SGM Egypt

'Have you ever traveled to Egypt?'

Similarly, neither -š nor lissah may occur in conditionals (11a,b), while fumr can (11c).

11a. law Sumr-ak saafir-it Masr laazim tə-zuur Pil-?ahraamaat

if ever-you travel.PERF.2sGM Egypt must.PTCP IPFV.visit.2sGM the-Pyramids

'If you ever visit Egypt, you must visit the Pyramids.' 
$\begin{array}{llll}\text { b. *law Ahmad gih } & \text { lissah } & \ldots \\ \text { if } & \text { Ahmad come.PERF.3sGM } & \text { yet } & \end{array}$ '*If Ahmad arrived yet, ...'

$\begin{array}{llll}\text { c. *law } & \text { suft-i-š } & \text { Ahmad } & \text { Pil-nahaar-dah } \\ \text { if } & \text { see.PERF.2sgm-EV-NEG } & \text { Ahmad the-day-this }\end{array}$

Intended reading: 'If you saw Ahmad today, ...'

Diachronically, Sumr is derived from the noun Sumr (=life/age), which is still productive in the language. Lissah, by contrast, is arguably derived from laysa, a negative morpheme from Classical Arabic. Similar to lissah, $-s ̌$ is generally assumed to be a phonological reduction of the noun šay? $(=a$ thing) in Classical Arabic, which came to function as an accusative adverbial NPI in certain grammatical contexts (Lucas, 2010).

Finally, recall that while maa can express negation by itself in certain contexts in CEA (as in 3a), -š cannot (cf. 9), thereby suggesting that -š is only formally negative, and that maa is the locus of semantic negation. We can thus summarize the "negativity" of these four elements as in Table (12).

\begin{tabular}{|l|l|l|l|l|}
\hline 12. & $-\check{s}$ & lissah & ?umr & maa \\
\hline Diachronic origin & $\begin{array}{l}\text { Noun used as an } \\
\text { NPI: šay } \text {-an }\end{array}$ & $\begin{array}{l}\text { Negative } \\
\text { morpheme: laysa }\end{array}$ & Noun: Pumr & $\begin{array}{l}\text { Negative } \\
\text { morpheme: maa }\end{array}$ \\
\hline $\begin{array}{l}\text { Compatible with } \\
\text { nonnegative contexts }\end{array}$ & No & No & Yes & \\
\hline Negativity & Formal & Formal & Nonnegative & Semantic \\
\hline
\end{tabular}

Returning now to the puzzle under discussion while taking formal negativity into account, it becomes clear that $-\check{s}$, a formally negative element, disappears in the presence of a nonnegative NPI such as fumr, but is retained in the presence of a negative NPI such as lissah. The phenomenon, however, is sensitive to locality: -š only disappears when Sumr is "close by" (i.e., in pre-negative position) but not when it is relatively distant (i.e., in postverbal position), as shown earlier by the contrast between (3) and (4). We may thus restate the puzzle of -š disappearance as in (13).

13. Within a local domain, -š is not spelled-out in the presence of an NPI that is formally nonnegative; otherwise it is phonologically realized.

To derive the generalization in (13) in a principled manner, and adapting an approach to negation and negative concord in Zeijlstra (2004, 2008), I propose a Split Neg analysis for CEA sentential negation, whereby maa is a (Pol)arity head, the locus of interpretable negation (marked as an [iNeg] feature), and -š is a Neg head specified for an uninterpretable negative feature (marked as [uNeg]). Licensing of Neg takes place under Agree with Pol, in the sense of Chomsky (2000, 2001), as illustrated in (14), ignoring irrelevant details.

14. [PolP $\left.m a a_{[\mathrm{iNeg}]}\left[\mathrm{NegP}-\check{S}_{[\mathrm{uNeg}]}[\mathrm{TP} \ldots .].\right]\right]$

$$
\rightarrow \text { Agree } \rightarrow
$$

In addition, based on Table 1, I assume that some NPIs (e.g., lissah) are formally negative, while others (e.g., Sumr) are not. In technical terms, the former are endowed with a [uNeg] feature, whereas the latter are not. Those that have a [uNeg] feature are licensed by Pol, either via Agree, or in a Spechead configuration (the latter argued for in Benmamoun 1997 for Moroccan Arabic NPIs). In addition, Pol also licenses NPIs semantically (under downward entailment (Ladusaw 1979), or nonveridicality (Giannkidou 1998)). I will further assume that "local domain" in (13) corresponds to a phase (i.e., CP and $v$ P; Chomsky 2001). Finally, I restate the generalization in (13) as an interface condition on Spellout of formal features licensed in the syntax, as in (15).

15. Minimize formal feature mismatch (MFFM): At Spell-out, minimize formal feature mismatch on licensees of the same licenser within a local domain.

Given these background assumptions, we can now see why -š disappears with Sumr, but not with lissah, given the representations in (16) and (17).

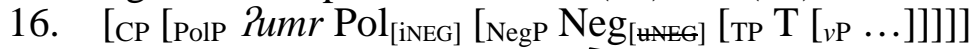

$$
\text { Npec-head } \backslash \text { Agree } \rightarrow
$$

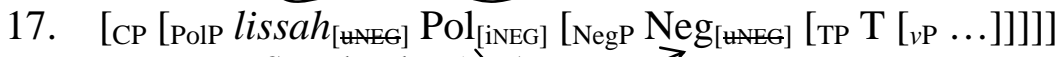
Npec-head Agree

While semantic licensing in both cases is unproblematic, syntactic licensing of the [uNeg] feature on Neg leads to mismatch in (16), but not in (17), hence forcing -š to delete in the former, but not the latter, as required by (15). 
Similarly, the fact that postverbal fumr does not induce -š suppression follows from MFFM being sensitive to locality: Since NPIs in postverbal position are within the $v \mathrm{P}$ phase, whereas -š is always in the CP phase, feature mismatch is rendered irrelevant at Spell-out and -š is retained (probably due to an input-output faithfulness constraint).

A problem arises, however, with the fact noted earlier that -š has to surface when fumr itself is the host of circumfixal negation (cf. 5), contrary to what we expect under the present analysis, since both elements are in the same phase in that case. Two questions arise here: First, why is fumr able to host negation in the first place? Second, why does $-s ̌$ surface in that case? For the first question, I suggest that, given its monosyllabicity, fumr has been reanalyzed as a preposition in the language. PPs in CEA can host negation, provided that their complement is a pronominal (18b); cf. Eid (1993).
18a. Iand-ii Sarabiyyah
at-me car
'I have a car.'
b. maa-Sand-ii-š Sarabiyyah
NEG-at-me-NEG car
'I don't have a car.'

As to why -š does not disappear when Gumr hosts negation, there are multiple possibilities to pursue. One is that the MFFM morphological principle in (15) does not apply at the single prosodic word level; rather, it applies only when the mismatched features occur on different prosodic words. A second possibility is to assume that in such contexts it is Neg, after being licensed by Pol, that licenses fumr as an NPI. Under that scenario, Neg and Sumr are not multiple licensees of the same licenser, and MFFM is inoperative. A third possibility is to assume that TP is a phase, or to re-define locality in nonphasal terms. Whatever the correct analysis turns out to be, the fact that -š is phonologically realized when fumr hosts negation is still reconcilable with the analysis presented here.

To sum up, a Split-Neg analysis of sentential negation in CEA allows us to formulate a principle to target the -š segment for deletion at Spell-out. This principle is crucially tied to the formal features of $-\check{s}$, the formal features (or lack thereof) of different NPIs, the mechanisms involved in licensing such features, as well as how local the $-\check{s}$ and the NPI are with respect to one another. If correct, the analysis not only explains away a morphosyntactic puzzle from negation contexts in CEA, but it also provides evidence that NPI phenomena, in addition to being a semantic dependency, may also involve formal feature licensing in a minimalist sense, with effects at the syntax-morphology interface.

Abbreviations used in the glosses of CEA data: 1, 2, 3 for first, second, and third person, respectively; SG = singular; PL = plural; $\mathrm{M}$ = masculine; $\mathrm{F}$ = feminine; $\mathrm{NEG}$ = negation marker; FUT = future; PERF = perfective; $\mathrm{IPFV}=$ imperfective; PTCP = participial; EV = epenthetic vowel.

\section{References}

Bahloul, Raja Mallek. 1996. Negation in French and Tunisian Arabic. In Eid, Mushira (ed.) Perspectives on Arabic Linguistics Vol. 8, 67-83.

Benmamoun, Elabbas. 1996. Negative polarity and presupposition in Arabic. In Eid, Mushira (ed.) Perspectives on Arabic Linguistics Vol. 8, 47-65.

Benmamoun, Elabbas. 1997. Licensing of negative polarity items in Moroccan Arabic. NLLT 15, 263-287.

Benmamoun, Elabbas. 2000. The Feature Structure of Functional Categories: A Comparative Study of Arabic Dialects. Oxford: Oxford University Press.

Chomsky, Noam. 2000. Minimalist Inquiries: The Framework. In Martin, Roger, David Micheals, and Juan Uriagereka (eds.). Step by Step: Essays on Minimalist Syntax in Honor of Howard Lasnik. Cambridge, Mass.: MIT Press. 89-156.

Chomsky, Noam. 2001. Derivation by Phase. In Kenstowicz, Michael (ed.) Ken Hale: a life in language. Cambridge, Mass.: MIT Press. 1-52.

Eid, Mushira. 1993. Negation and predicate heads. In Eid, M. and Iverson, G. (eds.) Principles and Prediction: The analysis of natural language. Amsterdam/Philadelphia: John Benjamins.

Giannakidou, Anastasia. 1998. Polarity Sensitivity as (Non)veridical Dependency. John Benjamins. Amsterdam.

Ladusaw, William. 1979. Polarity Sensitivity as Inherent Scope Relations. PhD Dissertation, University of Texas at Austin.

Lucas, Christopher. 2010. Negative -š in Palestinian (and Cairene) Arabic: Present and possible past. Brill's Annual of Afroasiatic Languages and Linguistics 2, 165-201.

Moritz, Luc and Daniel Valois. 1994. Pied-piping and specifier-head agreement. Linguistic Inquiry 25: 667-707.

Ouhalla, Jamal. 1990. Sentential negation, Relativized Minimality and the aspectual status of auxiliaries. The Linguistic Review 7, 183-231.

Ouhalla, Jamal. 2002. The structure and logical form of negative sentences in Arabic. In Ouhalla, Jamal, and Ur Shlonsky

(eds.) Themes in Arabic and Hebrew Syntax, pp. 299-320. Dordrecht: Kluwer Academic Publishers.

Pollock, Jean-Yves. 1989. Verb Movement, Universal Grammar, and the structure of IP. Linguistic Inquiry 20, 365-424.

Zeijlstra, Hedde. 2004. Sentential Negation and Negative Concord. Ph.D. Dissertation, University of Amsterdam.

Zeijlstra, Hedde. 2008. Negative concord is syntactic agreement. Ms., University of Amsterdam. 